\title{
Preparation and Characterization of Luminescent SCS and NCN Pincer Platinum Complexes Derived from 3,5-Bis(anilinothiocarbonyl)toluene
}

\author{
Ken Okamoto, Takaki Kanbara, Takakazu Yamamoto, and Akihide Wada \\ Chemical Resources Laboratory, Tokyo Institute of Technology, 4259 Nagatsuta, Midori-ku, \\ Yokohama, 226-8503 Japan \\ E-mail: tkanbara@res.titech.ac.jp
}

\section{Supplementary Information}

General Procedures. All solvents were dried and distilled prior to use, and the reactions were carried out under $\mathrm{N}_{2}$. NMR spectra were recorded on a JEOL JNM-EX-400 NMR spectrometer. Elemental analyses were carried out with a Yanaco CHN Corder MT-5 and a Yanaco SX-Elements Micro Analyzer YS-10. UV-visible absorption spectra and emission spectra were recorded on a Shimadzu UV-2550 UV-visible spectrophotometer and a Hitachi F-4500 fluorescence spectrophotometer, respectively. Samples for time-resolved measurements were excited at $400 \mathrm{~nm}$ using the second harmonic of an amplified mode-locked Ti:Sapphire laser and the luminescence was detected with a photomultiplier tube (Hamamatsu R928) and recorded using a digital storage oscilloscope, before transfer to a PC for analysis. TG analyses were carried out with a Shimadzu TGA-50 at a heating rate of $10{ }^{\circ} \mathrm{C} \mathrm{min}^{-1}$ under $\mathrm{N}_{2}$. Cyclic voltammetry was carried out with a Hokuto Denko HSV-100 standard voltammetry tool. A conventional three-electrodes configuration was used, with glassy carbon working electrode, platinum wire auxiliary electlode, and $\mathrm{Ag}^{+} / \mathrm{Ag}$ reference electrode. The voltammograms were adjusted to a ferrocene-ferrocenium couple $\left(\mathrm{Cp}_{2} \mathrm{Fe}^{+} / \mathrm{Cp}_{2} \mathrm{Fe}\right)$ as the standard $\left(E_{1 / 2}=+0.18 \mathrm{~V}\right.$ vs. $\left.\mathrm{Ag}^{+} / \mathrm{Ag}\right)$.

X-ray Crystallographic Study. The diffraction data were collected with a Rigaku Saturn $\mathrm{CCD}$ area detector with graphite monochromated $\operatorname{MoK} \alpha(\lambda=0.71070 \AA)$ at $-160{ }^{\circ} \mathrm{C}$. The data were corrected for Lorentz and polarization effects, and an empirical absorption correction was applied. The structure was solved by direct methods (SIR 92) and expanded using Fourier techniques. The non-hydrogen atoms were refined anisotropically. In the refinement all hydrogen atoms were included using the riding model with temperature parameter factors. 
(a) 1

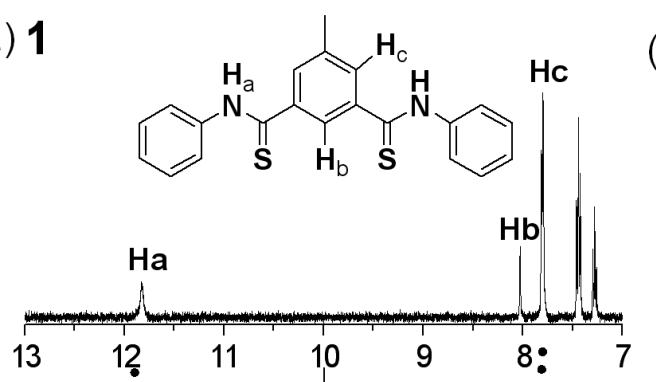

(b) 3 (c) 2

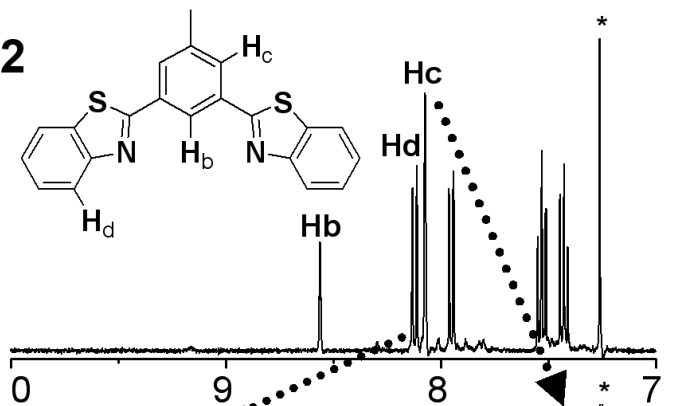

(d) 4

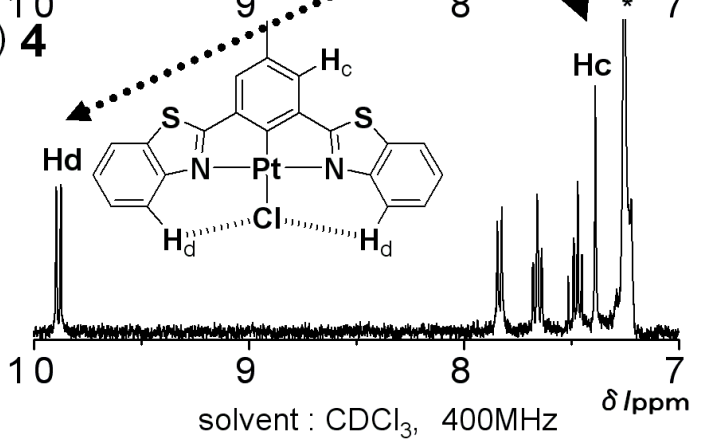

Figure S1. ${ }^{1} \mathrm{H}$ NMR spectra of (a) 1 and (b) 3 in DMSO- $d_{6}$ and (c) 2 and (d) 4 in $\mathrm{CDCl}_{3}$ at room temperature. $\mathrm{H}_{\mathrm{d}}$ in figures $\mathrm{S} 1(\mathrm{c})$ and $\mathrm{S} 1(\mathrm{~d})$ is denoted as $\mathrm{H}\left(4^{\prime}\right)$ in the text. 


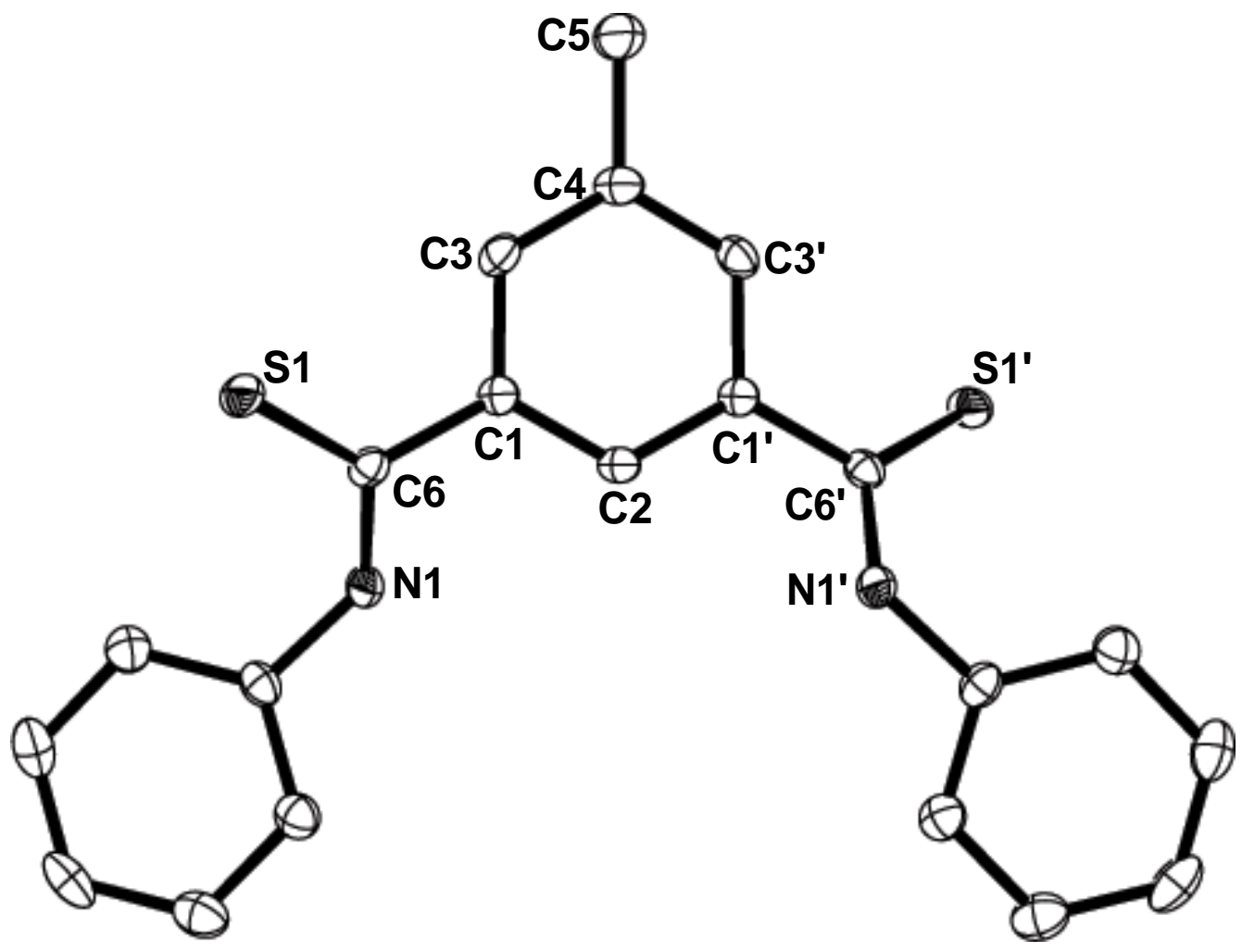

Figure S2. X-ray crystal structure of 1 with thermal ellipsoids drawn at the 50\% probability level. Hydrogen atoms are omitted for simplicity. 


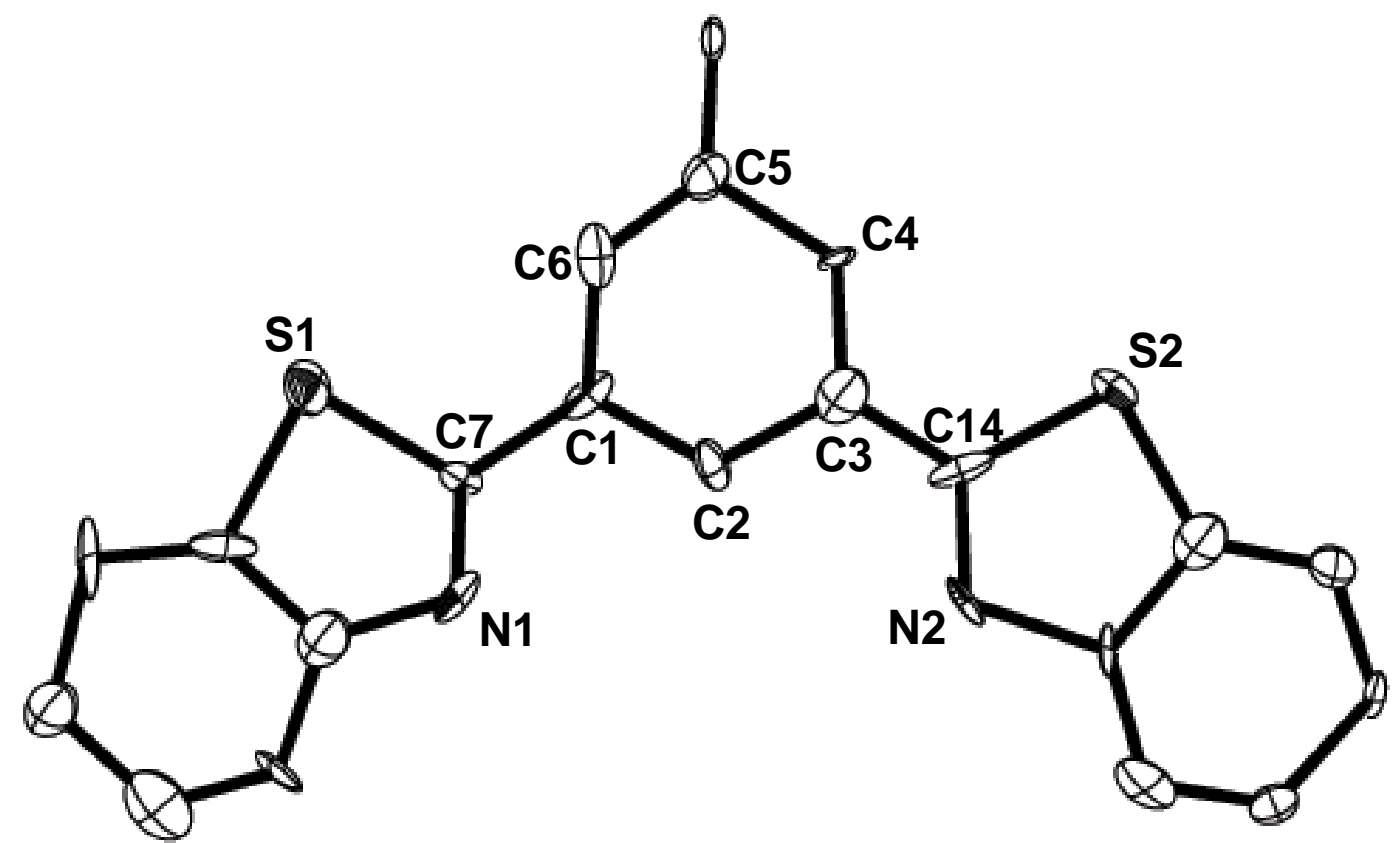

Figure S3. X-ray crystal structure of 2 with thermal ellipsoids drawn at the 50\% probability level. One of the two crystallographically independent molecules of $\mathbf{2}$ is shown. Hydrogen atoms are omitted for simplicity. 
(a)

(b)
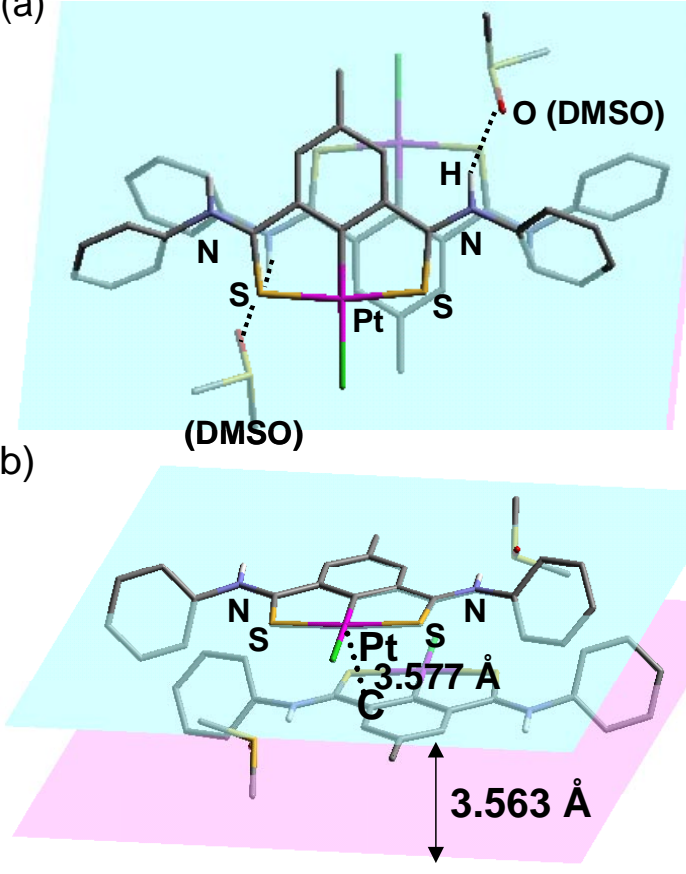

Pt...Pt $5.997 \AA ̊$ (c)

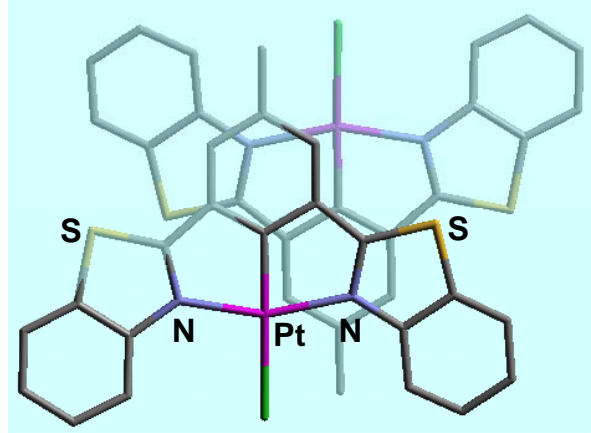

(d)

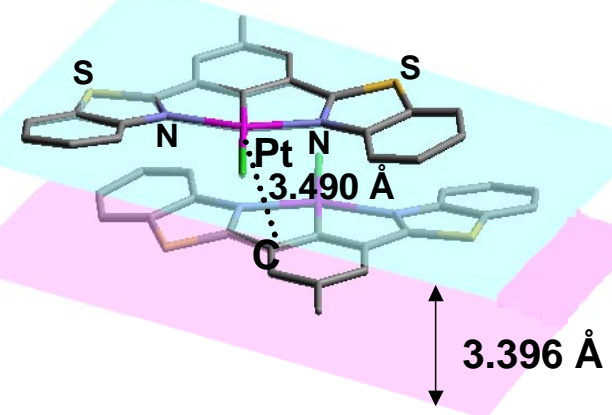

Pt...Pt $5.509 \AA$

Figure S4. Views of the molecular packing; (a) top view and (b) side view of $\mathbf{3}$ and (c) top view and (d) side view of $\mathbf{4}$. 
Table S1. Solvatochromism Data for 3

\begin{tabular}{ccc}
\hline \multirow{2}{*}{ solvent } & \multicolumn{2}{c}{ absorption $\lambda_{\max } / \mathrm{nm}$} \\
\cline { 2 - 3 } & $\pi-\pi^{*}$ & MLCT \\
\hline $\mathrm{MeOH}$ & 286 & 435 \\
EtOH & 286 & 445 \\
$\mathrm{CH}_{2} \mathrm{Cl}_{2}$-THF(3:2) & 292 & 465 \\
acetone & - & 468 \\
THF & 290 & 475 \\
\hline
\end{tabular}




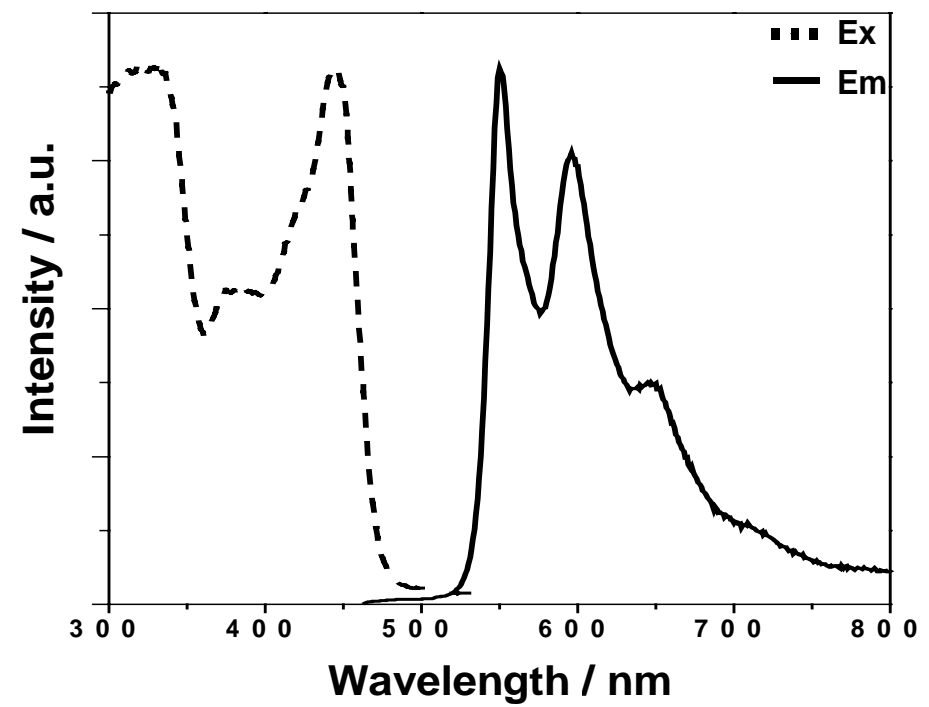

Figure S5. Emission and excitation spectra of 4 in a 3:2 mixture of $\mathrm{CH}_{2} \mathrm{Cl}_{2}$ and THF at room temperature. 
Table S2. Crystal data and details of the structure refinements for $\mathbf{1 , 2 , 3}$, and 4 .

\begin{tabular}{|c|c|c|c|c|}
\hline & 1 & 2 & 3.2DMSO & 4 \\
\hline Formula & $\mathrm{C}_{21} \mathrm{H}_{18} \mathrm{~N}_{2} \mathrm{~S}_{2}$ & $\mathrm{C}_{42} \mathrm{H}_{28} \mathrm{~N}_{4} \mathrm{~S}_{4}$ & $\mathrm{C}_{25} \mathrm{H}_{29} \mathrm{ClN}_{2} \mathrm{O}_{2} \mathrm{~S}_{4} \mathrm{Pt}$ & $\mathrm{C}_{21} \mathrm{H}_{13} \mathrm{ClN}_{2} \mathrm{~S}_{2} \mathrm{Pt}$ \\
\hline Formula Weight & 362.51 & 716.95 & 748.30 & 588.01 \\
\hline Crystal Color & yellow & pale yellow & red & orange \\
\hline Crystal System & monoclinic & monoclinic & monoclinic & monoclinic \\
\hline \multicolumn{5}{|l|}{ Lattice Parameters } \\
\hline $\mathrm{a} / \AA ̊$ & $11.239(12)$ & $7.5508(16)$ & $11.157(6)$ & 7.964(4) \\
\hline $\mathrm{b} / \AA ̊ \AA$ & $17.766(17)$ & $14.336(3)$ & $17.573(8)$ & $15.430(7)$ \\
\hline $\mathrm{c} / \AA ̊$ & $9.630(10)$ & $15.891(4)$ & $14.538(7)$ & $14.702(7)$ \\
\hline$\beta /^{\circ}$ & $113.112(13)$ & $103.788(3)$ & $100.779(8)$ & $96.796(8)$ \\
\hline $\mathrm{V} / \AA^{3}$ & $1768(3)$ & $1670.7(6)$ & $2800(2)$ & $1794.0(14)$ \\
\hline Space Group & $\mathrm{C} 2 / \mathrm{c}(\# 15)$ & $\mathrm{P} 2{ }_{1}(\# 4)$ & $\mathrm{P} 2{ }_{1} / \mathrm{n}(\# 14)$ & $\mathrm{P} 2{ }_{1} / \mathrm{c}(\# 14)$ \\
\hline $\mathrm{Z}$ value & 4 & 2 & 4 & 4 \\
\hline \multicolumn{5}{|l|}{ No. Reflections } \\
\hline \multicolumn{5}{|l|}{ Measured } \\
\hline Total & 6571 & 12566 & 19566 & 12764 \\
\hline Unique & 1941 & 5956 & 6282 & 4067 \\
\hline \multicolumn{5}{|l|}{$(\mathrm{I}>2.00 \sigma(\mathrm{I}))$} \\
\hline $\mathrm{D}_{\text {calc }} / \mathrm{g} \mathrm{cm}^{-3}$ & 1.361 & 1.425 & 1.775 & 2.177 \\
\hline Structure Solution & $\begin{array}{l}\text { Direct Methods } \\
\quad \text { (SIR92) }\end{array}$ & $\begin{array}{l}\text { Direct Methods } \\
\quad \text { (SIR92) }\end{array}$ & $\begin{array}{l}\text { Direct Methods } \\
\quad \text { (SIR92) }\end{array}$ & $\begin{array}{c}\text { Direct Methods } \\
\text { (SIR92) }\end{array}$ \\
\hline Reflection/Parameter & 11.93 & 9.16 & 15.64 & 13.26 \\
\hline \multicolumn{5}{|l|}{ Ratio } \\
\hline $\mathrm{R}(\mathrm{I}>2.00 \sigma(\mathrm{I}))$ & 0.0359 & 0.0805 & 0.0568 & 0.0308 \\
\hline $\mathrm{Rw}(\mathrm{I}>2.00 \sigma(\mathrm{I}))$ & 0.0515 & 0.1455 & 0.0741 & 0.0413 \\
\hline Goodness of Fit & 1.011 & 1.000 & 0.995 & 1.002 \\
\hline Indicator & & & & \\
\hline
\end{tabular}

